\section{Apresentação do dossiê "Elites em diferentes escalas: teoria e metodologia no estudo dos grupos dirigentes"}

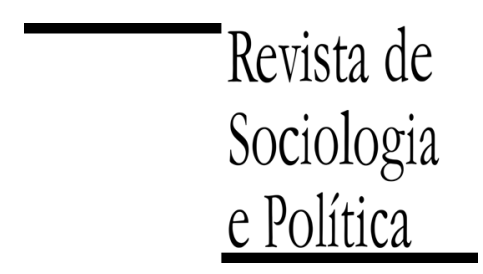

DOI 10.1590/1678-987314225201

\author{
Renato Perissinotto e Lucas Massimo \\ Recebido em 20 de Novembro de 2014. Aprovado em 30 de Novembro de 2014.
}

$\mathrm{O}$ tema das elites (políticas, econômicas e sociais) é particularmente presente na pauta de discussões do Núcleo de Pesquisa em Sociologia Política Brasileira (NUSP), vinculado ao Programa de Pós-Graduação em Ciência Política da Universidade Federal do Paraná. Desde a sua criação como grupo do CNPq, em 2002, os pesquisadores do NUSP vêm produzindo um amplo leque de pesquisas sobre as elites. Além das investigações empiricamente orientadas, os pesquisadores têm se dedicado também a discussões teóricas e metodológicas. No primeiro caso, preocupa-nos o alcance, os limites e vantagens de se estudar os fenômenos sociais e políticos a partir de um ponto de vista que privilegia os agentes capazes de controlar os recursos sociais, políticos e econômicos estratégicos, que lhes conferem um lugar privilegiado na disputa pelo acesso a posições de mando na sociedade. No segundo caso, figura como essencial para os pesquisadores do NUSP discutir as melhores maneiras de se chegar ao objeto, de coletar dados e de interpretá-los. Esforçamo-nos, nesse sentido, por manter sempre entrelaçadas as discussões metodológicas e teóricas com a prática da pesquisa empírica. Acreditamos que a pluralidade metodológica e teórica é mais vantajosa para o estudo dos objetos que nos interessam do que qualquer purismo.

Esse foi o espírito que nos levou a coordenar, entre 2007 e 2014, um Grupo de Trabalho nos encontros da Associação Nacional de Pós-Graduação (Anpocs) que tem como objeto exatamente o estudo das elites e dos grupos dirigentes. Esse Grupo de Trabalho da Anpocs conta com a presença de pesquisadores das mais diversas orientações teóricas e metodológicas, orientados pela teoria das elites, pela sociologia crítica de Pierre Bourdieu, por abordagens mais quantitativistas ou mais qualitativas. Avaliamos que um dos resultados mais palpáveis dessa pluralidade teórica e metodológica presente nas discussões da Anpocs foi elevar substancialmente a qualidade das pesquisas e dos debates realizados no interior do NUSP. Por essa razão é que, guiados pela mesma orientação, resolvemos organizar, nos dias 12 e 13 de setembro de 2013, o evento "Elites em diferentes escalas: teoria e metodologia no estudo dos grupos dirigentes", com financiamento da Coordenação de Aperfeiçoamento de Pessoal de Nível Superior (Capes) e apoio do Programa de Pós-Graduação em Ciência Política da UFPR.

O desenho do evento buscava introduzir uma unidade temática que, por sua vez, pudesse ser discutida a partir de ampla diversidade teórica e metodológica. Para tanto, três mesas diferentes foram organizadas: Estudos de elites econômicas, Estudos de elites estatais e, por fim, Estudos de elites partidárias. Para cada uma dessas mesas foram convidados pesquisadores de diversas orientações teóricas e metodológicas, oriundos de várias instituições universitárias, nacionais e internacionais. Para cada uma das mesas, também seguindo o 
critério da pluralidade, foram convidados debatedores especialistas no tema e de instituições diversas. A qualidade dos textos apresentados estimulou uma profunda discussão, amplamente favorecida pela combinação de unidade temática com pluralidade de abordagens. O presente número da Revista de Sociologia e Política é o resultado desse encontro.

Os trabalhos reunidos no primeiro bloco tratam das elites econômicas. $\mathrm{O}$ artigo que abre o dossiê apresenta a discussão sobre o rendimento analítico do Collective Mindset Analysis (CMA), um método empregado na pesquisa com os dirigentes de grandes corporações internacionais. Neste artigo Markus Polman, Stpehan Bar e Elizangela Valarini nos oferecem algumas sugestões acerca de como trabalhar com os trechos de falas extraídas das entrevistas com os Top Managers, particularmente em contextos de pesquisas comparadas, onde as idiossincrasias linguísticas podem comprometer a elaboração de bases de dados integradas.

O segundo artigo do bloco de estudos sobre as elites econômicas discute algumas características das elites econômicas argentinas entre 1810 e 1914. Roy Hora retoma neste artigo as dificuldades de combinar os agentes e o contexto em longas séries temporais.

$\mathrm{O}$ artigo de Paulo Roberto Costa encerra a primeira unidade temática, discutindo os matizes conceituais próprios das expressões recorrentes, como elite empresarial, dirigentes das entidades de representação do empresariado, elite econômica e dirigentes das grandes empresas.

Os artigos de Renato Perissinoto, Frederico de Almeida e Mariana Gené entram no dossiê circunscrevendo o bloco dos estudos sobre as elites estatais. $\mathrm{O}$ trabalho de Renato Perissinoto recupera um aspecto pouco examinado pela literatura do Estado Desenvolvimentista, o papel que os agentes decisores de política econômica (ou a sua dimensão especificamente volitiva) exerceram para a diferenciação das trajetórias industrializantes no Brasil e na Argentina. O texto de Frederico de Almeida defende o conceito de campo para confrontar os problemas metodológicos enfrentados na pesquisa com os ocupantes de altos postos no poder judiciário.

$\mathrm{O}$ artigo de Mariana Gené fecha o bloco de estudos sobre as elites estatais apresentando as vantagens e os gargalos encontrados na mobilização das entrevistas em profundidade para o estudo dos ocupantes do Ministério do Interior na Argentina pós-redemocratização. O trabalho apresenta algumas estratégias para se combinar diferentes modalidades de fontes (entrevistas, arquivos, matérias de jornal, textos normativos) no estudo dos processos de socialização política desse segmento da elite estatal.

O terceiro bloco temático é composto pelos estudos com as elites partidárias. Pedro Floriano Ribeiro apresenta um perfil dos integrantes das comissões executivas entre 1980 e 2013 formadas nos sete maiores partidos brasileiros. A partir dessas informações o autor propõe um modelo explicativo para as diferenças entre os partidos do ponto de vista organizacional. Seus resultados indicam que as instâncias internas dos partidos não são, como normalmente se supõe, controladas por lideranças parlamentares monolíticas, mas que, ao contrário, é necessário considerar os vínculos entre as elites partidárias, tanto na dimensão horizontal (congresso, governo federal e direção dos partidos) como na dimensão vertical (o que inclui as clivagens na estrutura organizacional em condições federativas)

O último artigo deste dossiê também tem foco sobre as elites partidárias. Stephanie Alenda examina as transformações de um dos principais partidos políticos chilenos, a Unión Demócrata Independiente (UDI), a partir das trajetórias dos nomes mais importantes da elite partidária. Combinando diversas 
fontes de dados, este artigo observa o processo de socialização política das elites dirigentes como uma evidência privilegiada para o estudo da institucionalização partidária.

A decisão por reunir em um dossiê o produto deste encontro exprime, em alguma medida, o desejo de fortalecimento do campo de estudos de elites, uma vez que os oito artigos sugerem uma diversificação da agenda de pesquisas sobre diferentes tipos de elites; mas além disso, queremos com esse fascículo sugerir que eventos de pequenas dimensões, concentrados em um tema específico, podem ser tão ou mais produtivos que os grandes congressos realizados periodicamente em diversas áreas do conhecimento. Grandes eventos científicos impõem um passivo elevado para as comissões organizadoras e custam caro para entidades de fomento. Este ônus se agrava com o convite a conferencistas estrangeiros que, não raro, são chamados a falar para plenárias muito amplas. Esperamos que os resultados do Colóquio Elites em Diferentes Escalas, reunidos nesse fascículo da Revista de Sociologia e Política, contribuam para vislumbrar outros formatos de eventos científicos.

Renato Perissinotto (monseff@gmail.com) é Doutor em Ciência Política pela Universidade Estadual de Campinas (Unicamp), professor dos programas de pós-graduação em Sociologia e Ciência Política da Universidade Federal do Paraná (UFPR) e editor-chefe da Revista de Sociologia e Política.

Lucas Massimo (lucasmassimo@gmail.com) é Mestre em Ciência Política pela Universidade Estadual de Campinas (Unicamo) e doutorando Ciência Política na Universidade Federal do Paraná (UFPR). 